\title{
Las escalas de lo humano. Pensar las infraestructuras del Antropoceno
}

\author{
The human scales. \\ Thinking about the Antropocene infrastructures
}

\author{
raúl rodríguez freire \\ Universidad Católica de Valparaíso, Chile \\ ORCID: 0000-0002-5397-7443 \\ rodriguezfreire@gmail.com
}

\section{RESUMEN}

En un intento por hacer comprensible el cruce de la corta y rápida historia humana con la profunda y lenta historia del planeta, se reflexiona sobre cómo las transnacionales del mundo actual, diseñado para sostener el consumo global, están destruyendo cada espacio vital, acción exterminadora -en la cual la responsabilidad individual no debe escamotearseque lleva paulatinamente a la muerte de la vida humana, así lo viviente -las bacterias, por ejemplo-, con toda seguridad, continúe su historia, es decir, resistirá una extinción más en el planeta. La comprensión de esta realidad es la tarea, urgente, de las "humanidades" en el siglo xxI.

Palabras clave: Globalización; biopolítica; devastación; heterogeneidad; nuevas tecnologías.

ABstRACT

In an attempt to make the crossing the short and quick human history with the deep and slow history of the planet understandable, it is re- 
flected on how the transnational companies of the current world, designed to sustain global consumption, are destroying every living space, exterminating action -in which individual responsibility should not be shirked- which gradually leads to the death of human life, thus the living-bacteria, for example will surely continue its history, that is, it will resist one more extinction on the planet. Understanding this reality is the urgent task of the "humanities" in the XxI century.

Keywords: Globalization; biopolitic; human devastation; heterogeneity; digital technologies.

El hombre no es comprensible sino en la totalidad terrestre.

André Leroi-Gourhan

Pero es que volverse humano puede transformarse en el ideal, y ahogarse bajo redundancias... Ser humano no debería ser un ideal para el hombre, que es fatalmente humano, ser humano debe ser el modo como yo, cosa viva, obedeciendo libremente el camino de lo que está vivo, soy humana.

Clarice Lispector

1. El mundo parecer haber sido más abordable, cuando no se lo conocía completamente, que ahora que podemos ver en detalle cada uno de sus rincones desde nuestros smartphones; y mediante este aparato, que opera a la velocidad de la luz, comprar lo que se quiera o se pueda desde y hacia cualquier continente. Un suceso político o económico ocurrido en una parte remota del mundo -aunque ello depende desde donde se lo observe- puede afectar -generalmente incrementar- el precio del pan o de la locomoción 
colectiva en Chile o México, y no sabemos, salvo las y los especialistas, por qué. Vivimos en un mundo hiperconectado, a escala no humana, logísticamente diseñado para sostener el consumo global, anclado en un modo de vida que, con tal de "responder a las necesidades materiales más evanescentes de las y los consumidores" (Manaugh, 2019, p. 38), está destruyendo cada espacio que busca productivizar. Bajo esta escala, planetaria, la responsabilidad individual en la destrucción del mundo pareciera no percibirse, pero, como señala Clark y Monteón (2019), "el impacto acumulativo de la insignificancia de cada uno es peor" (p. 22). Y ello, si se pusiera atención, se podría comprender preguntándose por la materialidad de los aparatos -entre ellos, el computador como objeto principal- con que hoy realizamos nuestro trabajo -intelectual o no-, lo que equivale a preguntarse por su modo de producción y circulación. Pero la humanidad misma posee una escala no humana y los medios o dispositivos lo testifican: lo humano ha devenido una fuerza geológica, articulada al subsuelo, transformado éste en un elemento más de la infraestructura del capital. La humanidad es una agencia sin sujeto, un hiperobjeto, al decir de Morton (2016), que nos obliga a "enfrentar algo que afecta nuestras ideas básicas sobre qué significa existir, qué es la tierra, qué es la sociedad” (p. 39). Más allá de los índices de carbono y la documentación estratigráfica, donde también, con igual o quizá mayor profundidad, se comprende la necesidad de reimaginar lo humano, es en la dominación intra e interespecie realizada para obtener los minerales que la tecnología que nos vincula necesita. El llamado Antropoceno ha cobrado fuerza a partir del capital fósil - siglo XIX-, como insiste Andreas Malm, pero va más allá. Piénsese en el coltán, un compuesto de columbita y tantalita que es indispensable para la fabricación de teléfonos móviles y otros dispositivos electrónicos, que se extrae de la República Democrática del Congo (RDC), donde se encuentra el 80\% de sus reservas mundiales. Guerra, esclavitud y trabajo infantil atraviesan su comercialización y nuestro consumo. O en las llamadas tierras raras, término que nombra un conjunto de elementos químicos, que también son indispensables para la tecnología de hoy, pero cuyo costo de extracción es muy alto. Estos 
minerales tienen millones de años y los llevamos en nuestros bolsillos, espacio en el que se imbrican la velocidad a la que nos arroja la digitalización de la vida con el tiempo lento de los minerales y su transformación en basura, como muestra Parikka (2021a) en Antropobsceno, donde señala que la velocidad de "la tecnología contemporánea... se ancla en la lentitud de la dinámica de la tierra” (p. 120).

2. En un intento por hacer comprensible el cruce de la corta y rápida historia humana con la profunda y lenta historia del planeta, indicado por Chakrabarty (2021), el musicólogo Gary Tomlinson (2017) representó la evolución de la "construcción de nichos" culturales -bioculturales-, permitiendo comprender "tanto las largas continuidades de esa historia, como el giro que ésta ha tomado recientemente, de manera abrupta” (p. 23). Su conclusión:

La tala de la mayoría de los bosques de Europa durante el último milenio, por ejemplo, ejerció un efecto colectivo sobre la biosfera mayor que el que podría haber producido cualquier población regional de pueblos del Paleolítico. Y el Antropoceno es el punto final actual de esta expansión, el repunte más reciente en el alcance y el ritmo de la construcción de nichos humanos (p. 27).

En tanto especie, el poder que ha ido desarrollando la humanidad mediante la construcción de nichos bioculturales le permitió direccionarlos, sólo que de manera contingente y azarosa cuando se la mira en conjunto, hasta el punto de abarcar no sólo el globo, sino el sistema planetario en su totalidad, el cual, gracias a la intervención humana, hoy está siendo dislocado, puesto que lo humano se ha convertido en una fuerza geológica capaz de alterar el clima durante los próximos milenios, hasta el punto de hacer emerger la posibilidad de la propia extinción. La vida o lo viviente, por su parte, continuará. El planeta, por tanto, no debiera preocuparnos. Ha aguantado muy bien seis extinciones previas y seguramente la nuestra no lo inmutará. Lo que nos debiera entonces interesar es la vida en cualquiera de sus manifestaciones. 
3. Este escenario, al que hemos dado lugar, debe ser asumido, tenemos que asumirlo, considerando al mismo tiempo la profunda historia humana, la corta historia del capital y la azarosa contingencia que nos cruza diariamente, teniendo en cuenta que no sólo la historia misma -conceptual y disciplinariamente- está en ruina, también los saberes en su conjunto, pues éstos fueron estructurados a partir de las necesidades del capital, necesidades que no se corresponden con las de la vida, en particular con las necesidades de la vida humana. Y si la escala global tiene prioridad, como ha señalado la antropóloga Anna Tsing, es porque se trata de "la escala del modelo", que tiende, bajo la lógica de la escalabilidad, a anular la singularidad de las vidas, humanas y no humanas. Por ello es que no debemos desconsiderar la cotidianidad, y no sólo porque "el impacto acumulativo de la insignificancia" es mayor del que creemos, sino porque precisamente se necesitan millones de actos cotidianos para disolver ese impacto acumulativo. Los saberes deben reconfigurarse para poder aprehender las transformaciones en curso, aún más teniendo en cuenta que una sola disciplina no puede abarcarlas, ni comprenderlas si se mantiene en los límites que la modernidad impuso.

4. En Las raíces del mundo, un libro de entrevistas que recoge su trayectoria como paleontólogo, a propósito de una polémica respecto del tiempo de duración de unos contenedores de residuos radioactivos, que durarán algunos siglos, Leroi-Gourhan (1984) señalaba que ni siquiera 5.000 años serían suficientes para establecer políticas de habitabilidad del mundo: "Un proyecto que cubriera 20.000 años sería razonable." Y agrega: "si tenemos en cuenta lo que es el pasado del hombre, podemos en efecto, en condiciones óptimas de conservación, trazar una trayectoria que teóricamente debiera llegar más allá de 100.000 años, pero que sería ya muy buena si cubriera 20.000" (p. 114). Y poco más adelante, concluye: "Ya se puede calcular sin grandes dificultades el tiempo de supervivencia material del homo sapiens, pero cada cual se limita a previsiones de muy corto plazo." Incluso la historia de la especie humana es pequeña en relación a la historia del planeta. 2000 años, decía Gould 
(1999), son, a propósito del fin del segundo milenio de nuestra era, geológicamente hablando, "apenas un abrir y cerrar de ojos... un periodo increíblemente corto. Tanto que ni siquiera podemos medirlos con nuestros instrumentos" (p. 35). ¿Cómo entonces imaginar el cruce de diversas escalas? ¿Cómo analizar con ellas, por ejemplo, una novela? ¿Y por qué debiéramos hacerlo? Para Tsing (2019), el Antropoceno da lugar a una composición espacial diferenciada, a la que da el nombre de "manchas" (p. 178). Éstas consisten en estructuras de paisajes, tales como plantaciones, suburbios, complejos industriales, instalaciones logísticas, entre otras, que se inscriben en geografías planetarias desiguales. Se trata de infraestructuras que, articulando diversas escalas espaciales y temporales, alteran la tierra, el agua y la atmósfera, transformando radicalmente los paisajes. De ahí que Tsing insista que el estudio del Antropoceno debe comenzar por el análisis de las infraestructuras y sus diversas configuraciones y escalas, teniendo en cuenta que no es posible determinar a priori por dónde comenzar. La escala a investigar "emerge a partir de los problemas asociados con la estructura de paisaje" (p. 184). Pero me estoy adelantando, pues el descubrimiento del tiempo profundo debe ser entendido para comprender mejor su relevancia en la necesidad de repensar lo humano bajo el Antropoceno. De todas maneras, por ahora me interesa establecer la importancia de la infraestructura como un elemento determinante para la globalidad -o escalabilidad- contemporánea del capital, pues es a partir de ella que se reduce la heterogeneidad del mundo, esto es, de la vida.

5. Buffon, señaló Leroi-Gourhan (1971), asienta "los dos problemas que iban a inflamar el siglo xIx: la posición zoológica del hombre y el carácter vertiginoso de las épocas geológicas” (p. 11). El nombre de Darwin es de sobra conocido, no así el de James Hutton, quien dio cuenta del llamado "tiempo profundo". Puesto que la humanidad, al decir de Leroi-Gourhan (1971), "no es comprensible sino en la totalidad terrestre" (p. 13), entonces las ciencias humanas deben asumir la noción de especie y la relación que ésta mantiene con lo geológico, pues lo geológico nos constituye, 
a nosotros y a los medios con los que interactuamos con el mundo. Ahora bien, la geología tiene dos ejes de desarrollo: el tiempo profundo, cuyo descubrimiento determinó su base disciplinaria, y el movimiento continuo - placas tectónicas, esto es, temblores y terremotos, además de volcanes. Hasta el siglo XVIII, y algo entrado también el siglo XIx, el tiempo de la tierra respondía o se circunscribía al tiempo mosaico: 6.000 años. De ahí que las propuestas de Hutton hayan sido consideradas como un escándalo para la sociedad bien pensante de su época. En 1785, leyó ante la Sociedad Real de Edimburgo lo que tres años después sería publicado como Theory of the Earth. A partir de su observación de formaciones rocosas, dio cuenta de un movimiento de erosión y recomposición que no podía tener lugar en miles, sino en millones de años. "El resultado de nuestra investigación”, sentenció Hutton -en lo que hoy es su frase más famosa-, "es que no encontramos ningún vestigio de un inicio ni hay perspectivas de un final". Afirmarlo en aquel tiempo no era fácil y la reflexión de Hutton debió dar paso a las pruebas. Con todo, el cálculo de Hutton seguía siendo menor respecto de la verdadera edad de la tierra. Fue recién a inicios del siglo xx que se logró comenzar a estimar con mayor precisión una cifra, y hoy sabemos que la tierra tiene alrededor de 4570 millones de años. Para el paleontólogo Gould (1992), “el tiempo profundo es tan difícil de asimilar, tan ajeno a nuestra experiencia ordinaria que se configura como un obstáculo para nuestro entendimiento [...], es algo tan extraño que realmente sólo podemos comprenderlo metafóricamente" (pp. 20-21), cuestión que quisiera destacar, pues sólo la imaginación, y en particular la imaginación literaria y artística, parece en condiciones de asistirnos en la comprensión de lo que implica una escala no humana. En Basin and range -Valle y cordillera-, libro reseñado por Gould (1992), John Mcphee (1981) escribió:

Para representar todo el tiempo de la tierra, extiende las manos y observa la línea de la vida de una de ellas. El cámbrico [ubicado entre 570 y 500 millones de años] empieza en la muñera, y la extinción del Pérmico está en el extremo exterior de la palma. El Cenozoico 
entero es la huella dactilar, y con un simple golpe de lima de uña podrías erradicar toda la historia de la humanidad (p. 124).

El libro de Mcphee es un intento por dar cuenta a los no especialistas en qué consiste la geología; de ahí que para Gould no deje de estar atravesado por los mitos que aún dominan la disciplina, como la supuesta objetividad y la centralidad del trabajo de campo. Con todo, nos interesa también cómo Mcphee imagina el segundo eje: "Si me ordenaran simplificar todo lo escrito en una sola frase, escogería esta: la cumbre del Everest está compuesta de piedra caliza marina" (p. 24). Hutton descubrió -o imaginó, pues no tenía cómo probarlo- que la tierra se agita en un movimiento incesante de erosión y recomposición; y como era amigo de James Watts, el perfeccionador de la máquina a vapor inventada por Thomas Newcomen, no podía sino ver aquí una máquina operando a semejanza de un motor, con un centro caliente, tan caliente como para derretir la piedra y de vez en cuando lanzarla hacia la superficie, modificándola. Señala Gould (1992):

Dos claves en las observaciones de Hutton alimentaron el descubrimiento del tiempo profundo: primero, el reconocer el granito como una roca ígnea, esto representa una fuerza restauradora de edificación (de manera que la tierra puede reciclarse indefinidamente, en vez de erosionarse hasta la ruina); y, segundo, la adecuada interpretación de los relieves geográficos como límites entre ciclos de edificación y erosión (lo que suministra evidencia directa de episodios de renovación más que de corta y lineal decrepitud)" (p. 24).

6. Fue el "descubrimiento" de Hutton, entonces, lo que articuló la zoología con el tiempo profundo, lo orgánico con lo inorgánico; y es lo que nos permite ver de qué manera hoy lo local opera indefectiblemente de manera global, se trate del costo de las necesidades básicas o del costo del transporte. Aunque un ejemplo más concreto lo podemos encontrar en nuestros teléfonos, prótesis inescindibles en nuestra cotidianidad. Alrededor de un $75 \%$ de la tabla periódica se encuentra representado en un Smartphone; y su reunión, ha mostrado el Servicio Geológico de los Estados 
Unidos, se logra adquiriendo minerales, como Benetton, de los cinco continentes. He aquí algunos de los empleados y su procedencia: Argentina y Chile proporcionan litio para las baterías, lo mismo que China y Australia; de Sudáfrica, Rusia y Canadá viene el platino, que opera como catalizador de procesos electrónicos -circuitos, condensadores y placas-; de Bielorrusia, Canadá y Rusia viene también el potasio, usado para pantallas; el tántalo, para condensadores, de Ruanda, Brasil y Congo; desde hace siglos, de México, China y Perú se adquiere la plata para circuitos; el indio, responsable de la conducción eléctrica de la pantalla, se encuentra en China y República de Corea; el estaño de China, Indonesia, Birmania y Perú, para pantallas de cristal líquido y circuitos; el grafito de India y China y se lo utiliza para ánodos -baterías. Sólo la arena industrial, empleada para producir LEDs, pantallas, altavoces y motores de vibración, proviene de Estados Unidos. De Europa, nada, aunque yacimientos de esfalerita, un sulfuro del que se obtiene el indio, también se encuentran en Alemania, Suecia y España. Y no podía faltar el petróleo, llamado oro negro, del que se fabrica el plástico que compone más de la mitad de un teléfono. "La historia de los medios", señaló Jussi Parikka, "se funde con la historia de la tierra", historia(s) que se guarda(n) -o llevan- en nuestros bolsillos. Si al recurso de los minerales sumamos, por un lado, la forma en que se extraen y, por otro, las condiciones laborales que para ello se requieren, nos daremos cuenta que el vertiginoso presente que tejen los dispositivos tecnológicos y la velocidad que nos permiten descansa sobre múltiples niveles de explotación, cuestión que las llamadas humanidades digitales, el movimiento aceleracioncita y el neo-operaísmo italiano suelen pasar por alto: la nube está en la tierra, y bien asentada en ella. Ha señalado Parikka (2021b), en Geología de los medios:

la minería de datos puede ser un término de moda para nuestra era digital actual, pero solamente es posible gracias al tipo de minería que asociamos con los suelos y su excavación. La cultura digital comienza en las profundidades y los tiempos profundos del planeta. 
Tristemente, la mayoría de las veces esta historia es demasiado obscena como para celebrarse con asombro (p. 60).

El estudio de la materialidad de los medios, hoy en boga en las humanidades y las ciencias sociales, pasa por alto la materia misma que los posibilita. Nuestros dedos se deslizan sobre una pantalla configurada a partir de una mezcla de óxido de indio y óxido de estaño. Su luz, si se trata de una pantalla LED, proviene del Galio. Qué ocurre con todos estos minerales una vez que los teléfonos "mueren" debiera ser una pregunta para la que debemos comenzar a buscar no sólo respuestas, sino también soluciones.

7. La historia profunda, entonces, es una historia de metáforas y de lecturas, puesto que, como ha señalado Parikka, la marca de la huella humana "la Tierra la lleva en sí como un archivo", pero, al mismo tiempo, partes de ese archivo se acoplan, mediante diversas prótesis tecnológicas, a lo humano. "Esto nos lleva a rastrear", agrega Parikka (2021b), "la importancia de lo inorgánico en la construcción de los medios antes de que estos se conviertan en medios: sus tiempos y lugares verdaderamente profundos en las minas y los minerales ricos en elementos de tierras raras" (p. 30). Lo geofísico, que en sí constituye el pliegue de diversas escalas, emerge aquí como un ámbito clave para comprender la cultura medial del siglo XxI y su impacto no sólo en el desarrollo de las comunicaciones, sino también, al mismo tiempo, en la reconfiguración de lo humano y su incidencia en la destrucción del planeta. Baste pensar en el cobre, un elemento dúctil y maleable, cuya alta conductividad eléctrica le ha permitido convertirse en el material más utilizado para fabricar cables eléctricos y otros elementos necesarios para la producción de componentes electrónicos. Ahora bien, la mejorara de su ductilidad y su maleabilidad requieren de un proceso de refinamiento que resulta altamente contaminante, al generarse gases como el arsénico o el anhídrido sulfuroso. "Es la tierra", señala Parikka (2021b) más adelante, "la que provee de recursos a los medios y los hace posible: los minerales, los materiales de 
(sacados de) la tierra, las potencialidades de su realidad geofísica que permiten que tengan lugar los medios técnicos" (pp. 40-41).

8. De ahí que Parikka (2021b) hable de "naturalezas mediales", concepto que anuda el doble vínculo entre medios y naturaleza, en tanto esferas que se co-constituyen (p. 42) -lo cual implica considerar en su estudio realidades no humanas y humanas, como el trabajo. A partir de Donna Haraway y el modo en que operacionalizó el término "naturculturas" -naturecultures-, término con el que busca aprehender el continuo de microinteracciones que se dan entre la "naturaleza" y la "cultura" - por lo que ya no pueden pensarse como dos términos separados o componiendo una distinción-, Parikka interroga el continuum entre los medios y el mundo material -mineral- del que dependen para existir, un mundo al que, una vez producidos, regresan de distintas maneras, ya sea para estudiarlo o explotarlo. En palabras de Parikka (2021b), las naturalezas mediales se refieren al doble vínculo que se da entre los medios y la cultura digital. Por una parte, los medios dependen de las llamadas posibilidades naturales, como los minerales de tierras raras, la producción de diversos materiales y el suministro de energía, que todavía depende en gran medida de los combustibles fósiles. Por otra parte, los medios comportan también la forma epistemológica de escanear, mapear, identificar y, en última instancia, comprender qué es esta "naturaleza". "Los medios visuales contribuyen a dar forma a los conceptos científicos" con que intentamos conocer el medioambiente y ello en el campo de la geología es determinante para la existencia de la propia disciplina. Ahora bien, donde con mayor claridad se revelan los lazos y relaciones de la naturaleza medial es "en los contextos extremos de explotación y daño ambiental” (p. 27). Aquí hay que considerar no sólo los minerales que se requieren para la producción de un teléfono, sino también la basura electrónica en la que éste prontamente se convertirá, restos cuyas consecuencias aún no se han logrado determinar. Comprender el efecto de la obsolescencia programa es, así, una tarea que puede llevarse a cabo pensando en la "naturaleza medial": "las tecnologías mediales que nos brindan las visiones 
reales e imaginadas de la realidad geofísica disponible para la minería son las mismas que se convertirán, bajo la forma de escombros y desechos, en los futuros fósiles tecnológicos." Comprender, entonces, la materialidad de los medios, más allá de sus soportes, es determinante. Hay que insistir en que la famosa nube, centro de operaciones del llamado trabajo cognitivo, está alojada en un edificio que, para mantenerse a la temperatura requerida, se encuentra en el norte global, mientras los aparatos se fabrican -bardworken el sur global, con sueldos que no pocas veces apenas permiten la sobrevivencia. Las naturalezas mediales, entonces, permiten un análisis del tiempo profundo y su imbricación en un presente atravesado por una división internacional del trabajo, una división radicalmente desigual, que reinscribe nuevas formas de colonialismo. De ahí que Parikka (2021a) prefiera referirse a la nueva época geológica como "antropobsceno": "el norte proporciona lo fresco, el sur provee lo barato (el trabajo)” (p. 58).

9. Son estas historias y reflexiones, entonces, las que deben llevarnos a pensar en las escalas, pero no de cualquier manera ni a cualquier costo. El paleoclimatólogo Curt Stager publicó no hace mucho El futuro profundo. Los próximos 100.000 años de vida en la Tierra (2012), libro en el que muestra la fuerza geológica humana, capaz de afectar no los 100, sino los 500 mil años que vienen. Ello implica, por ejemplo, saltarse una o quizá dos eras del hielo por venir. Con todo, Stager parece preocuparse más por un hipotético futuro antes que por un ya traumático presente, donde el clima se encuentra fuera de quicio, como diría Hamlet. De ahí que sea oportuno recordar que para Gould (1999) "la escala temporal humana es la única que debiéramos tener en cuenta en nuestros postulados ecológicos o éticos". Y concluye:

Una ética ecológica apropiada no debe fijarse como objetivo el futuro lejano de la vida en otros planetas -o en este mismo, agrego-, sino que debe preocuparse de la calidad de nuestra vida y de la vida de las demás especies aquí y ahora. Estas también son extinciones 
de las que somos causa involuntaria $-\mathrm{y}$, agrego nuevamente, también voluntaria- (p. 53).

Y poco más adelante, señala: "no debe inquietarnos lo que le suceda al planeta", pues es hoy que hay que intervenir. De ahí que ante la pregunta sobre qué especies habría que proteger con mayor urgencia responda:

salvémoslas todas, si podemos, no tengo prioridades concretas, confío en un principio general: no debemos dejar que perezca ninguna especie si está en nuestras manos impedirlo. Sin embargo, hemos modificado los climas y los entornos ambientales tan profundamente que es inevitable que de ello se deriven algunas extinciones. El segundo principio consiste en no considerar que ese pequeño escarabajo que nadie conoce carece de importancia. Es tal vez cierto desde el punto de vista estético, pero no desde el farmacológico (Gould, 1999, p. 54).

El Antropoceno no marca un peligro para la tierra, sino para quienes hoy la habitamos. Pensar en escalas no debe impedirnos ver $-\mathrm{y}$ sentir-, como dice el mismo Stager (2012):

los gases que calientan el mundo, acidifican los océanos y cambian la composición isotópica de nuestros cuerpos no son solo palabras sobre el papel o fórmulas en la pizarra de algún profesor. Nos llenan los pulmones, golpean la cara de quien ahora mismo lee estas palabras, vibran en la garganta de la profesora que dicta su clase (p. 305).

Me interesa destacar la insistencia de Stager (2012) en el efecto sobre el cuerpo y en la cotidianidad del cambio climático, pues si tendemos a reducir o a descartar la relevancia de la responsabilidad individual en la destrucción del mundo -pasado por alto, repito-, "el impacto acumulativo de la insignificancia", ello se debe -aventuro- a que la escala personal o local suele pasarse por alto. Señaló al respecto Philippe Descola: 
raúl rodríguez freire

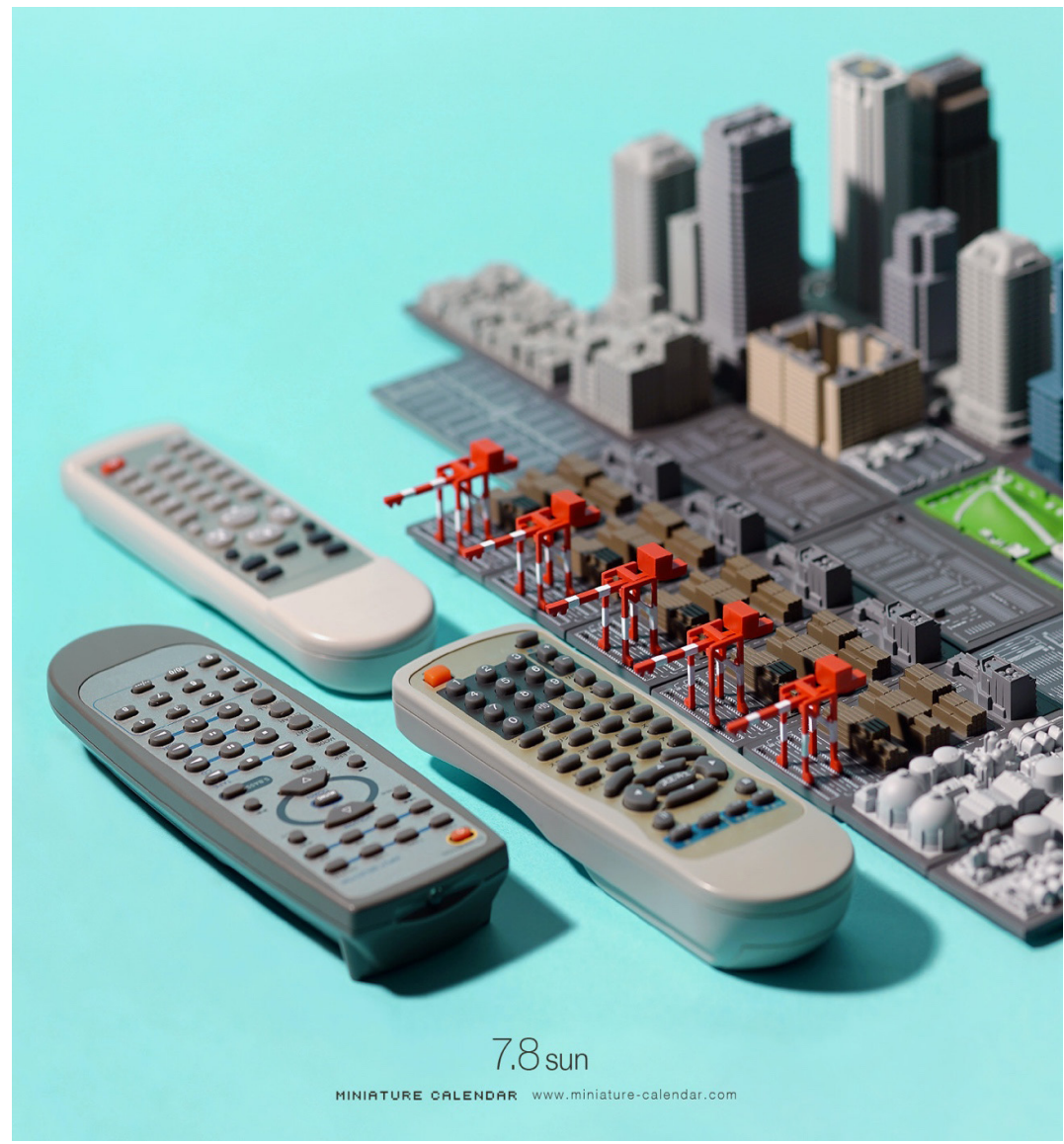

Figura 1. Tatsuya Tanaka (2018), "Buque de carga remoto".

para enfrentar la emergencia del cambio climático, ahora tenemos que aprender y propagar la idea todavía nueva de que nuestro destino no se limita a un enfrentamiento más o menos hostil entre los humanos y la naturaleza por medio de la técnica, como la tradición moderna quiso hacernos creer, sino que depende totalmente de los billones de acciones y retroacciones por las cuales engendramos cotidianamente las condiciones medioambientales que nos permiten habitar el planeta Tierra (p. 24). 
10. La necesidad de comprender la importancia de las escalas y sus relaciones ha sido relevada por la pandemia que aún atravesamos, aunque, paradójicamente, por su desconsideración. La velocidad de propagación de, por ejemplo, la peste negra, de la que Boccaccio fue un narrador, no se compara con la propagación del coronavirus, que, a la fecha, ha recibido respuestas meramente nacionales y, por ello, ineficaces. De manera que debemos dirigirnos hacia la estética para enfrentar este problema, pues el arte es uno de los lugares en que aparece con fuerza y creatividad. Entre los artistas que logran dar cuenta de esta relación se encuentra el trabajo de Tatsuya Tanaka (Figura 1), que invierte las escalas mediante un potente zoom para poner en escena escalas ampliadas, representadas por pequeños objetos cotidianos. Sus montajes fotográficos nos muestran, por ejemplo, una lechuga que se transforma en un volcán, un calcetín en una pista de fórmula 1, unas piezas de dominó en un restaurante de comida rápida, unas escobillas de ropa en una plantación de arroz, unos tornillos en un bosque de pinos y unos pernos en una usina, una navaja en un aeropuerto, unos rayadores en edificios que muy bien podrían estar en el Down Town de Chicago, de la misma manera que unos corchetes se transforman en New York. Objetos muy cotidianos nos permiten aprehender el vínculo de la escala personal o familiar con la globalidad del capital, y ello en conexión con el tiempo, pues el trabajo de Tanaka se encuentra inscrito en el tiempo. Desde el 20 de abril de 2011, viene publicando diariamente, y de manera ininterrumpida, una imagen montada en su página web, titulada Miniature Calendar, articulando así el tiempo con el espacio.

11. Quisiera detenerme en la imagen titulada "Buque de carga remoto", una miniatura a escala $1 / 2500$. En su simplicidad, pareciera que sólo da cuenta de la relevancia de la infraestructura en la cotidianidad. Pero su potencia no se reduce a "jugar" simplemente de materiales de desecho, viejos controles remotos y sus placas, pues teniendo en cuenta lo que hemos venido revisando, debemos detenernos en la propia materialidad de los objetos empleados por Tanaka y lo que literal y metafóricamente representan al mismo 
tiempo. Aquí, la mirada de Tanaka pone en escena la cotidianidad atravesada por una escala ampliada. Esos buques y ese puerto están imaginados a partir de desechos electrónicos y chatarra, restos, al decir de Parikka (2021a, p. 63), que permanecen y, por ello mismo, deben ser comprendidos como elementos que operacionalizan una temporalidad que se pliega sobre las situaciones e infraestructuras materiales del Antropoceno. En otras palabras, puesto que estos restos requirieron para su fabricación de determinados minerales, que ahora devienen desechos, forman "parte de cuestiones más amplias de diseño e infraestructura, de pasados y de obsolescencia en el ahora presente, contemporáneo” (p. 67). Y dada su composición, no lo hacen de manera pasiva, sino que, con su pura presencia, contribuyen a performar el presente, contribuyendo a su inhabitabilidad. Agrega Parikka (2021a):

[En tanto desecho, el resto] no es una réplica pobre del supuesto original, sino en sí mismo ya un acontecimiento que tiene su propia duración y existencia, su propia lógica y temporalidad, parte de una serie de situaciones y acontecimientos. No señala simplemente el lugar de algo desaparecido, sino que funciona como su propia fuerza generativa (p. 74).

Por supuesto, los restos del Antropoceno pueden adquirir diversas escalas, desde estos viejos controles remotos hasta ciudades enteras, pasando por islas como Hashima -en Japón- o centros comerciales abandonados. Constituyen manchas, al decir de Tsing (2019), que reconfiguran un paisaje posthumano, pero aquí lo posthumano debe entenderse literalmente, esto es, sin humanos. En este puerto, los humanos no aparecen; y ello no se debe a la escala, sino a su modo de funcionamiento: tanto los barcos como el puerto han sido automatizados y son, por tanto, comandados a distancia. Este telepuerto de Tanaka recuerda el "Global Container Terminals" de Bayona, Nueva Jersey, cuyo lema es "Where tomorrow arrives today" -Donde mañana llega hoy. Aquí, la presencia humana se limita a una mera supervisión, realizada desde una oficina alejada

${ }^{1} \mathrm{El}$ énfasis es nuestro. 
de los muelles y sus grúas. Los algoritmos hacen todo el trabajo, permitiendo un modo de funcionamiento heredado de la Toyota y su modo de producción postfordista. Como ha señalado Björn Henriksson, director de tecnología de la empresa sueca ABB Marine \& Ports, los sistemas automatizados, como los de Bayona, "permiten operaciones remotas, es decir, el control remoto del barco que llega al puerto [remote control of the ship-to-shore] -STS- y las grúas apiladoras, así como también el monitoreo remoto de puertas automáticas, donde la intervención bumana es la excepción". "Conocí el análisis de Henriksson gracias a Geoff Manaugh (2019), quien ha escrito sobre el espacio infraestructural y procesional de Bayona y

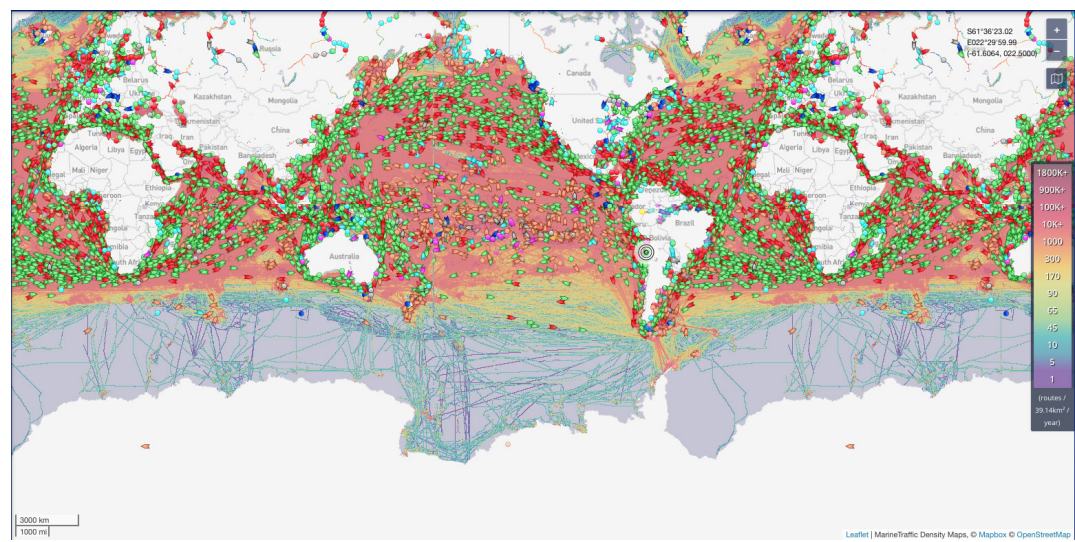

Figura 2. Tráfico marino:

https://www.marinetraffic.com/en/ais/home/centerx:-123.8/centery:-34.3/zoom:2

la ausencia de humanos, que intervienen sólo de manera remota y durante tan sólo unos segundos, puesto que los algoritmos hacen gran parte del trabajo logístico o casi todo el trabajo, más bien, puesto que la intervención humana no supera los 10 segundos cada vez que se tiene que revisar el control asistido. Y agrega:

\footnotetext{
${ }^{2}$ El énfasis es nuestro.
} 
La infraestructura portuaria marina automatizada combina la robótica a escala del paisaje con la logística de distribución justo a tiempo (just-in-time) para crear entornos laberínticos donde el cuerpo humano está fuera espacial y temporalmente. Las características arquitectónicas de estos puertos son mínimas; estos no son entornos definidos por estructuras fijas, sino por complejas reglas espaciales capaces de reorganizarse casi en tiempo real. El puerto es un espacio automatizado según lo establecido por algoritmos de envío y almacenamiento (p. 37). ${ }^{2}$

12. Esta imagen del tráfico marino (Figura 2), tomada en tiempo real el 01 de octubre de 2021, da cuenta de un movimiento del que no solemos tener noticias: el devenir logístico del mundo, gracias a "las cadenas de suministro planetarias" que articulan los puertos. Éstos, inscritos en bordes costeros, parecieran ser espacios marginales, pero su relevancia es determinante para el funcionamiento del capital global y su escalabilidad (Tsing). Su propósito económico y técnico explícito, dice Manaugh (2019), "es servir a la metrópoli sin dejar de ser metafóricamente invisible o de operar logísticamente fuera de la vista" (p. 39). De manera que su relevancia infraestructural es determinante para la temporalidad contemporánea, puesto que en ellos la geografía o el espacio es "reempaquetado como tiempo" (p. 39), articulando así diversas y heterogéneas escalas. Se trata, al decir de Ned Rossiter (citado por Manaugh, 2019), de un "complejo organizacional":

[Está hecho] de sistemas tecnocráticos y estéticos diseñados para modular el mundo como un "patrón informático, organizado" de formas flexibles. No restringida por el gobierno soberano o las fronteras nacionales, la ciudad logística es una forma recombinatoria que intenta estandarizar la acumulación de capital desde el nivel micro de los aparatos algorítmicos hasta el nivel macro de las infraestructuras globales.

En los puertos, entonces, tiene lugar el "esclarecimiento del trabajo infraestructural de las conexiones multiescalares, que van desde los microniveles a lo planetario" (Parikka, 2021a, p. 136). 
13. Pensemos en el cobre, teniendo en cuenta que Chile es su mayor productor mundial (28\%), razón por la cual consiste en el principal producto de exportación nacional. El cobre sale hacia China -el principal socio comercial de Chile, que consume el 54\% de la producción mundial de cobre-, fundamentalmente en cátodos -placas de alta pureza, que se obtienen en el proceso de electrorrefinación y electroobtención-, por el puerto de Antofagasta y regresa por el puerto de Valparaíso, convertido en cable, pues, junto al aluminio y el cobalto, es uno de los materiales más importantes en la fabricación de un smartphone. Los teléfonos inteligentes que llevamos en nuestros bolsillos nos conectan no sólo con nuestros contactos, también con lo más profundo de la tierra. Comentando en su página web la obra Mineral Visión, Abelardo Gil-Fournier recuerda que "el cobre, elemento indispensable de la infraestructura digital, aparece en primer plano como una presencia material, bruta y a-lingüística. Frente a la explotación industrial de minerales y personas, el diálogo electrónico es un encuentro de escalas y duraciones, la geológica y la humana". Así como los puertos son infraestructuras que reempaquetan el espacio como tiempo, los smartphones bien pueden considerarse microinfraestructuras que reempaquetan el tiempo -humano- como espacio - global-, al permitir conexiones que articulan lo local y lo planetario. Y no sólo porque nos permiten llamar sin dilación desde Valparaíso a Londres o Pekín, sino por el tiempo profundo de los minerales que dan lugar a su existencia y a la nuestra. La historia de los medios, concluye $\mathrm{Pa}$ rikka (2021a), "deviene historia de la arquitectura", así como "los objetos mediales, incluso la operacionalidad, devienen cuestiones de infraestructura", manchas sin las cuales la vida, tal como la conocemos, ya nos sería posible, pero, al mismo tiempo, manchas que vuelven inhabitable el propio mundo que vivimos. Sin lugar a dudas, tendremos que escoger, teniendo en cuenta, como hemos visto, que una infraestructura nunca es una cosa, sino una "relación o una infinita regresión de relaciones" (Parikka, 2021a, p. 107). Lo humano ya no puede ser comprendido, sino como un haz atravesado y constituido por distintas escalas. Y es la comprensión de este acontecimiento, y no ya la moderna distinción entre cultura 
y naturaleza, de lo que deben encargarse las "humanidades" en el siglo XXI.

\section{BIBLIOGRAFÍA}

Chakrabarty, D. (2021). Clima y capital. La vida bajo el Antropoceno. Santiago: Mimesis.

Clark, T. y Monteón, Y. (2019). Escala. Perturbaciones escalares. Revista de Filosofía Universidad Iberoamericana, 51(146), 18-43. < https://doi.org/10.48102/rdf.v51i146.3>.

Gould, s. J. (1992). La flecha del tiempo. (Traducción de C. Acero). Madrid: Alianza.

Gould, s. J. (1999). El año 2000 y las escalas del tiempo. En J. C. Carrièrre, J. Delumeau, U. Eco y J. Gould (Eds.), El fin de los tiempos (pp. 15-66). (Traducción de J. Zulaika). Barcelona: Anagrama.

Leroi-Gourhan, A. (1971). El gesto y la palabra. (Traducción de F. Carrera). Caracas: Universidad Central de Venezuela.

Leroi-Gourhan, A. (1984). Las raíces del mundo. (Traducción de M. Vassallo). Barcelona: Juan Granica.

Mcrhee, J. (1981). Basin and Range. New York: Farrar, Straus and Giroux.

Manaugh, G. (2019). Where Tomorrow Arrives Today. Infrastructure as Processional Space. (L. Young, Ed.). Machine Landscapes: Anchitectures of the Post Anthroposce (Anchitecture Design) (pp. 3643). London: John Wiley \& Sons.

Morton, T. (2016). Ecología oscura. Sobre la existencia futura. (Traducción de F. Borrajo). Barcelona: Paidós.

PArIKKa, J. (2021a). Antropobsceno y otros ensayos. Medios, materialidady ecología. Santiago: Mimesis.

Parikka, J. (2021b). Geología de los medios. (Traducción de M. Gonnet). Buenos Aires: Caja negra.

STAGER, C. (2012). El futuro profundo. Los próximos 100.000 años de vida en la Tierra. (Traducción de J. Lluís Riera). Barcelona: Crítica. 
Las escalas de lo humano. Pensar las infraestructuras...

Tomlinson, G. (2017). Two Deep-Historical Models of Climate Crisis. South Atlantic Quarterly 116(1), 19-31. <https://doi. org/10.1215/00382876-3749282>.

Tsing, A. (2019). Viver nas ruinas. Paisagens multiespécies no Antropoceno. Brasilia: Mil Folhas do IEB. 